PLPB: Pendidikan Lingkungan dan Pembangunan Berkelanjutan

DOI: https://doi.org/10.21009/PLPB.181.03

DOI: 10.21009/PLPB

\title{
THE EFFECT OF GENDER DIFFERENCES \\ ON PRO ENVIRONMENTAL BEHAVIOR IN DIRECTORATE GENERAL BINAPENTA\&PKK, MINISTRY OF MANPOWER, 2016
}

\author{
Meyrina Pronityastuti \\ Kementerian Ketenagakerjaan
}

meynoemail@gmail.com

\begin{abstract}
The purpose of this research is to determine the effect of gender differences on pro environmental behavior among employees of Directorate General Binapenta and PKK, Ministry of Manpower. Samples of 126 respondents were taken by taking a simple random sampling technique from the employees. This research used non test instruments, measuring pro environmental behavior.

The research results show that there were diffences of pro environmental behavior which affected by the gender. Based on the result, the pro environmental behaviors of female employees are better than male employees. Therefore, in order to improve pro environmental behavior of employees, gender of the employees should be considered as influential factors.
\end{abstract}

Keywords : gender, pro environmental behavior.

\begin{tabular}{|l|l|l|l|}
\hline Volume XVIII & Nomor 01 & Maret 2017 & ISSN 1411-1829 \\
\hline
\end{tabular}




\section{Pendahuluan}

Masalah pencemaran lingkungan terus berkembang seiring dengan perkembangan teknologi, ekonomi, sosial, budaya, dan politik. Perkembangan teknologi dan industrialisasi mendorong konsumsi masyarakat yang berlebihan yang berpengaruh pada tingkat pencemaran lingkungan.

Di beberapa kota besar di Indonesia, pencemaran juga telah terjadi misalnya pencemaran air yang dibuktikan dengan merosotnya kualitas air sehingga tidak dapat dikonsumsi manusia, akibat limbah domestik maupun limbah industri. Limbah industri yang dibuang ke sungai kadangkala masih mengandung senyawasenyawa kimia terutama limbah B3 (Bahan Berbahaya Beracun) dengan konsentasi yang di atas nilai ambang batas.

Ditambah lagi persoalan rendahnya kepedulian terhadap lingkungan memperburuk permasalahan lingkungan. Padahal, jika hal ini terus dibiarkan, maka berdampak kepada kesehatan masyarakat baik secara fisik maupun psikis.

Oleh karena itu, dalam upaya untuk mencegah dan meminimalisir dampak degradasi kualitas llingkungan, diperlukan kepedulian terhadap lingkungan yang dimunculkan dengan mewujudkan perilaku pro lingkungan (pro environmental behavior) yang sebaiknya dilakukan oleh karyawan. Blok (2014:8-9) Perilaku pro lingkungan ini dibuktikan dengan tindakan yang memperhatikan lingkungan seperti, memanfaatkan air dan energi listrik secara efisien, menggunakan pemakaian dan memakai alat transportasi umum sehari-hari yang tidak mencemari lingkungan dan perilaku-perilaku lainnya yang berkontribusi positif terhadap lingkungan. Pemerintah, melalui Kementerian Lingkungan Hidup berusaha mensosialisasikan perilaku pro lingkungan salah satunya dengan mengeluarkan peraturan Inpres NO.2/2008 tanggal 5 Mei 2008 dan Instruksi Menteri Pekerjaan Umum Tahun 2008 tentang Penghematan Energi dan Air dengan memprakarsai penerapan Eco Office. Eco Office adalah kantor ramah lingkungan yang bertujuan menciptakan lingkungan kantor yang bersih, indah, nyaman serta menyehatkan. Sasaran diterapkannya Eco Office tersebut adalah mengubah sikap dan perilaku individu di kantor untuk lebih peduli lingkungan dan melakukan penghematan biaya operasional kantor terkait aspek lingkungan.

Dengan demikian, perilaku pro lingkungan dapat diartikan sebagai perilaku yang berusaha meminimalisir dampak negatif dari tindakan seseorang terhadap lingkungan dalam kehidupan sehari-hari. Perilaku ini dapat berupa pemeliharaan sumber daya yang spesifik, (air, udara, tanah), pengurangan konsumsi sumber energi (listrik, minyak, gas), mendaur ulang (mendaur ulang kertas, plastik, dll) serta memelihara lingkungan.

Beberapa penelitian terkait perilaku pro lingkungan telah dilakukan. Penelitian relavan berikut dilakukan oleh Deanne L Turnbull (2010), tentang Employee Pro Environmental Behaviours: A Workplace culture as a driver for social change. Hasil penelitian difokuskan pada perilaku pro lingkungan yang dilakukan di tempat kerja oleh karyawan perusahaan berpengaruh terhadap perilaku di rumah Loverock (2013:9).

Menurut pendapat Kaiser dan Wilson (2004), secara umum perilaku pro lingkungan dapat dikelompokkan menjadi 6 (enam) dimensi perilaku pro lingkungan yakni energy conservation, transportation and mobility, waste avoidance, consumerism, recycling dan vicarious conservation behavior Rojzen (2013:9).

\begin{tabular}{|l|c|c|c|}
\hline Volume XVIII & Nomor 01 & Maret 2017 & ISSN 1411-1829 \\
\hline
\end{tabular}


Salah satu faktor yang membentuk perilaku pro lingkungan, menurut penelitian yang dilakukan oleh Gifford dan Nisson (2014) adalah gender. Gender berpengaruh terhadap perilaku tindakan seseorang terhadap lingkungannya. Menurut Robert (2014:13) dalam jurnalnya mengatakan Wanita cenderung mempunyai sikap, kepedulian dan perilaku pro lingkungan dibandingkan pria.

Istilah gender menurut Oakley (1985) berarti a matter of culture, it refers to the social classification into masculine and feminine. Menurut Hilary M. Lips mengartikan gender as cultural expectations for women and men. Suzanne Wiliiams, Janet Seed dan Adelina Mwau (1994) mengartikan gender sebagai berikut: eople are born female or male but learn to be girls and boys who grow into women and men. They are taught what the appropriate behaviour and attitudes, roles and activities are for them and how the should relate to other people. This learned behaviour is what makes up gender identity and determines gender roles.

Dengan demikian dapat dikatakan bahwa gender merupakan suatu konstruksi sosio-kultural terhadap pembagian peran, kedudukan, tugas dan perilaku antara wanita dan laki-laki dalam masyarakat, yang sifatnya secara relatif dapat berubah sesuai adat istiadat dan kultur yang masih berlaku. Konsep gender yang ada pada masyarakat merupakan sifat yang melekat pada kaum laki-laki dan perempuan yang dibentuk oleh faktor - faktor sosial dan budaya, sehingga lahir beberapa peran.

Seseorang baik pria atau wanita mempunyai sikap, perasaan dan perilaku yang biasanya terhubung dengan dirinya dapat disebut sebagai identitas gender yang merupakan identifikasi seseorang terhadap nilai tertentu seperti sex biologis, psikologis dan sosial. Oleh karena itu, seseorang dianggap masyarakat berperilaku sesuai dengan gendernya jika penampilan, perilaku, sikap, minat serta nilai-nilai yang dianutnya sesuai dengan ciri gendernya, yang berimplikasi pada nilai tanggung jawab yang diemban oleh gender pria dan wanita.

$\begin{array}{ccr}\text { Bagi } & \text { gender } & \begin{array}{r}\text { wanita, } \\ \text { dengan }\end{array} \\ \text { diidentifikasikanteristik }\end{array}$ feminin. Sifat feminin terdiri dari ulet, pengertian, setia, sabar, kreatif, lemah lembut, hangat, sensitif terhadap kebutuhan orang lain, simpatik, dan pengertian.

Bagi gender pria, diidentifikasikan

dengan karakteristik maskulin dikarakteristikan terdiri dari sifat kompetitif, ambisius, dominan, berani, rasional, bertindak sebagai pemimpin,asertif, analitis, individual dan agresif.

Berdasarkan beberapa penelitian, gender berpengaruh dalam pembentukan perilaku pro lingkungan (pro environmental behavior). Salah satunya adalah penelitian yang dilakukan oleh Faye V. Mcdonald. Penelitiannya menjelaskan bahwa pada faktor intrapersonal, faktor demografi yakni pendidikan, gender, umur, pendapatan, serta tempat tinggal menunjukan korelasi langsung yang signifikan terdapat perilaku pro lingkungan.

Gender seseorang dapat mempengaruhi orang tersebut dalam pola pikir dan pengambilan keputusan atas masalah dan fenomena di sekitarnya serta mempengaruhi tanggung jawab yang diembannya.

\begin{tabular}{|l|l|l|l|}
\hline Volume XVIII & Nomor 01 & Maret 2017 & ISSN 1411-1829 \\
\hline
\end{tabular}




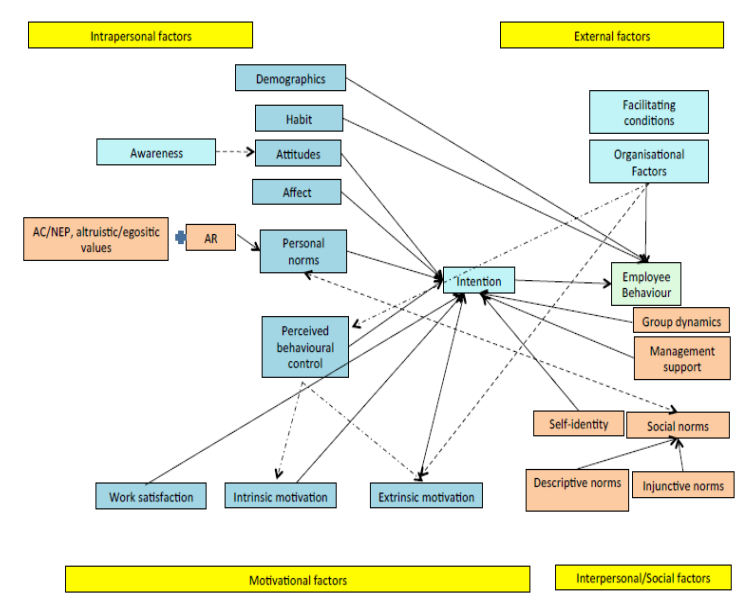

Gambar 1.2 Model Employee Pro Environmental Behavior

Berdasarkan penelitian yang dilakukan oleh Zelezny, Poh Pheng Chua dan Christina Aldrich, diketahui bahwa dibandingkan pria, wanita lebih mempunyai ecocentrism (kepedulian terhadap alam, biosfer dan semua makhluk hidup) dibandingkan pria, serta wanita muda dibandingkan pria, menujukkan tanggung jawab pribadi yang lebih kuat untuk memperbaiki lingkungan.

\section{Metodologi Penelitian}

Secara umum penelitian ini bertujuan mengetahui pengaruh perbedaan gender pria dan wanita terhadap perilaku pro lingkungan (pro environmental behavior) karyawan di lingkungan Ditjen Binapenta dan PKK, Kemnaker. Berdasarkan perumusan masalah yang telah dikemukakan maka secara khusus tujuan penelitian ini adalah :

1) Perbedaan perilaku pro lingkungan antara karyawan dengan persepsi gender pria dan gender wanita.

2) Perilaku pro lingkungan lebih positif dilakukan oleh gender wanita dibandingkan oleh gender pria

Populasi dalam penelitian ini adalah karyawan Ditjen Binapenta dan PKK, Kemnaker. Dengan jumlah sampel yang diambil berjumlah 126 orang. Teknik pengambilan sampel dilakukan dengan teknik simple random sampling. Jumlah sampel ditentukan sebanyak 126 karyawan mewakili seluruh populasi yang ada dengan jumlah karyawan wanita sebanyak 63 orang dan karyawan pria sebanyak 63 orang.

Pengumpulan data yang digunakan adalah teknik non tes dengan instrument berupa angket/kuesioner. Skala pengisian kuesioner memiliki lima katagori jawaban yaitu pernyataan yang diajukan dilengkapi dengan lima alternatif jawaban.

Untuk instrument mengukur perilaku pro lingkungan, peneliti memodifikasi dari alat ukur General Ecological Behavior Scale (GEBS). GEBS dikembangkan oleh Kaiser dan Wilson dengan skala yang meliputi 6 (enam) jenis perilaku yaitu:

1. Energy conservation : perilaku dapat terlihat dari efisiensi dan penghematan energi, serta mulai untuk beralih kepada energi terbarukan

2. Mobility and transportalion : perilaku ini terkait dengan pemilihan transportasi untuk mobilitas sehari hari, untuk mengurangi dampak polusi dan mengurangi pemakaian bahan bakar

3. Waste avoidance: perilaku ini terkait pada mengurangi pemakaian barangbarang yang dapat menghasilkan limbah dan menggunakan barangbarang lama untuk dipakai kembali.

4. Consumerism : perilaku terkait dengan berbelanja makanan untuk dikonsumsi, baik makanan yang pro lingkungan

5. Recycling : perilaku penggunaan barang yang sudah tidak terpakai menjadi barang lain yang berguna,

6. Vicarious, social behaviors toward conservation : perilaku ini dilakukan dengan berperan aktif mengelola lingkungan dalam suatu masyarakat, meningkatkan kesadaran banyak orang untuk peduli lingkungan,

\begin{tabular}{|l|l|l|l|}
\hline Volume XVIII & Nomor 01 & Maret 2017 & ISSN 1411-1829 \\
\hline
\end{tabular}




\section{Hasil Penelitian dan Pembahasan}

Penelitian ini melibatkan dua variabel, yaitu Pro Environmental Behavior (Y) sebagai variabel terikat, sedangkan Gender (X) sebagai variabel bebas. Adapun secara rinci pembahasan hasil analisis dan pengujian hipotesis penelitian diuraikan sebagai berikut:

1. Hipotesis Pertama Perbedaan Perilaku Pro Lingkungan Karyawan berdasarkan persepsi Gender Pria dan Gender Wanita

Dari hasil perhitungan, dengan kriteria tolak $\mathrm{H}_{\mathrm{o}}$ jika nilai $\mathrm{F}_{\text {hitung }}>\mathrm{F}_{\text {tabel }}$ pada taraf signifikansi $\alpha=0,05$ diketahui bahwa nilai $F_{\text {hitung }}=4,301>F_{\text {tabel }}=4,00$ pada taraf signifikansi $\alpha=0,05$, Dengan demikian maka $\mathrm{H}_{0}$ ditolak dan $\mathrm{H}_{1}$ diterima. Berdasarkan hal tersebut maka dapat disimpukan bahwa hipotesis yang diajukan peneliti dapat diterima bahwa terdapat perbedaan yang sigifikan perilaku pro lingkungan antara gender pria dan gender wanita.

2. Hipotesis Kedua Perilaku Pro Lingkungan (Pro Environmental Behavior) Karyawan dengan Gender Wanita Lebih Positif Dibandingkan Karyawan dengan Gender Pria

Dari hasil penghitungan data skor mean kelompok gender pria dan wanita, dapat dilihat bahwa adanya perbedaan skor perilaku pro lingkungan. Dari skor perilaku pro lingkungan bagi karyawan wanita diperoleh nilai mean sebesar 49, 67; median sebesar 50; modus sebesar 59; varians sebesar 97, 71 dan standar deviasi sebesar 9,88. Sedangkan skor perilaku pro lingkungan bagi karyawan pria diperoleh nilai mean sebesar 46,17 ; median sebesar 46; modus sebesar 49; varians sebesar 16,41 dan standar deviasi sebesar 4,05. Dari nilai mean perilaku pro lingkungan pada kedua kelompok dapat dilihat bahwa karyawan wanita lebih tinggi perilaku pro lingkungan yang dimiliki dibandingan karyawan pria

Bagi gender wanita, diidentifikasikan dengan karakteristik feminin. Sifat feminin terdiri dari ulet, pengertian, setia, sabar, kreatif, lemah lembut, hangat, sensitif terhadap kebutuhan orang lain, simpatik, dan pengertian. Sifat gender yang memperdulikan lingkungan sekitarnya berpengaruh terhadap perilaku yang dilakukannya. Di sisi lain, gender pria dikonstruksikan secara sosial budaya untuk bersikap dominan, independen, pencari nafkah dan bertindak sebagai pemimpin dalam keluarga, sehingga cenderung lebih dominan menggunakan lingkungan untuk kepentinngannya. Ditambah lagi, gender pria dikonstruksikan bersifat maskulin yang bertindak secara rasional berdasarkan pengetahuan yang dimiliki. Sehingga perilaku pro lingkungannya pun dipengaruhi oleh pengetahuan dari masing-masing individu.

\section{Kesimpulan}

pengaruh perbedaaan gender terhadap perilaku pro lingkungan karyawan Ditjen Binapenta dan PKK, Kementerian Ketenagakerjaan, maka dapat disimpulkan sebagai berikut :

Pada karyawan dengan gender wanita dan gender pria terdapat perbedaan pada perilaku pro lingkungan, dimana karyawan gender wanita memiliki perilaku pro lingkungan lebih tingi dari pada karyawan dengan gender pria;

Dari hasil penelitian dan kesimpulan yang telah dijelaskan sebelumnya, maka saran dari peneliti

\begin{tabular}{|l|l|l|l|}
\hline Volume XVIII & Nomor 01 & Maret 2017 & ISSN 1411-1829 \\
\hline
\end{tabular}


adalah sebagai berikut: (1) Pemangku kebijakan dalam upaya untuk mensosialisasikan green office, perlu memperhatikan faktor perilaku pro lingkungan yang ditunjukkan oleh karyawan. Sehubungan dengan hal tersebut, maka perlu adanya payung hukum berupa peraturan yang jelas sehingga membentuk perilaku pro lingkungan di kantor secara lebih baik; dan (2) Dalam upaya untuk mewujudkan hal tersebut di atas maka perlu memperhatikan faktor gender dalam mensosialisasikan pro environment behavior. Hal ini dapat dilakukan dengan mengadakan kegiatan bersama-sama di luar kantor, untuk lebih dekat dengan alam, dan melalui kegiatan ini dapat lebih mengenal karakteristik karyawan.

Oleh karena gender berpengaruh terhadap pro environment behavior maka pendekatannya berbeda bagi gender pria dan wanita. Meningkatkan pro environment behavior pada gender pria, dapat dilakukan dengan meningkatkan pengetahuan karyawan pria terhadap lingkungan serta tindakan-tindakan yang pro llingkungan, misalnya dengan melakukan kegiatan secara aktif bersama-sama dengan konsep green environment atau kegiatan seminar kesehatan bertema lingkungan. Sedangkan gender wanita cenderung bersifat altruistic, sehingga program dapat dilakukan dengan mensosialisasikan gerakan pro environment behavior melalui kegiatan sosial darma wanita misalnya pada acara bazar mendorong membeli barang-barang pro lingkungan.

$$
\text { Bagi penelitian selanjutnya, }
$$
perilaku pro lingkungan tidak hanya dipengaruhi gender akan tetapi masih banyak variabel lain yang mempengaruhi. Oleh karena itu, diperlukan kajian penelitian lebih lanjut terhadap variabel yang belum diteliti. Serta dapat diperluas, tidak hanya pada lingkungan kantor, akan tetapi penelitian dapat dilakukan baik pada lingkungan sekolah maupun di masyarakat.

\section{Daftar Pustaka}

Blok, Vincent, et.al. "Encouraging Sustanainability in the workplace: a survey on the pro environmental behaviour of university employees". Journal of Cleaner Production. Elsevier Ltd.: 2014.

Fausia, L dan Nasyiah. Gender Dalam Kawasan DAS Citanduy : Kajian Aktivitas Reproduktif Dan Produktif Perempuan Dalam Sumberdaya Alam. Pusat Studi Pembangunan Institut Pertanian Bogor \& Partnership for Governance Reform in Indonesia UNDP.2005.

Funder, DC. "Personality", Annual Review of Psychology Vol 52. 2001.

Handayani dan Sugiarti. 2002. Konsep dan Teknik Penelitian Gender. Universitas Muhammadiyah Malang Press. Malang.2002.

Indeks Kualitas Lingkungan Hidup Indonesia 2013 ,Jakarta : KLHK.

Kaiser, F. "A general measure of ecological behavior". Journal of Applied Social Psychology, 28 (5).1998.

Lips, Hilary M. Sex and Gender: An Introduction. London: Myfield Publishing Company.1993.

Loverock, Deanne L. Turnbull. "Employee Pro Environmental Behaviors : Workplace Culture as A Driver for Social Change". Thesis Royal Roads University. 2010.

Rojzen, Nina. et.al. "A competence Model for Environmental Education." Environment and Behavior $\mathrm{XX}(\mathrm{X})$ ) Sage Publication.2013.

\begin{tabular}{|l|l|l|l|}
\hline Volume XVIII & Nomor 01 & Maret 2017 & ISSN 1411-1829 \\
\hline
\end{tabular}


William, S., Seed, J. and Mwau A. "The Oxfam Gender Training Manual". Oxfam, Oxford UK. 1994.

Zelezny, C. Lynette., Poh Pheng Chua, Christina Aldrich. "Elaborating on Gender Differences in Environmentalism." Journal of Social Issues. Vo.56. 2000. 